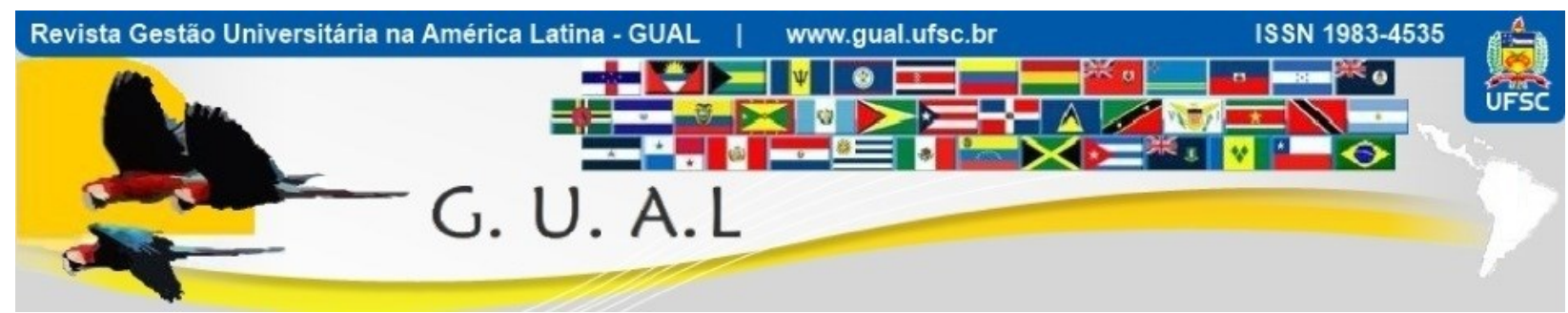

DOI: http://dx.doi.org/10.5007/1983-4535.2014v7n2p308

\title{
APRENDIZAGEM A DISTÂNCIA: UM ESTUDO À LUZ DA ABORDAGEM CONSTRUTIVISTA
}

\section{DISTANCE LEARNING: A STUDY IN THE LIGHT OF THE CONSTRUCTIVIST APPROACH}

Naldeir dos Santos Vieira, Doutorando Universidade Federal dos Vales do Jequitinhonha e Mucuri - UFVJM naldeir@yahoo.com.br

Airton Cardoso Cançado, Doutor Universidade Federal de Tocantins - UFT airtoncardoso@yahoo.com.br

Marcelo Cambraia de Alvarenga, Mestre Universidade Federal dos Vales do Jequitinhonha e Mucuri - UFVJM $\underline{\text { marcelocambraia@ig.com.br }}$

Juliana Borges Martins, Mestre Universidade Federal dos Vales do Jequitinhonha e Mucuri - UFVJM juliana.borges@prof.ead.ufvjm.edu.br

Recebido em 17/março/2013

Aprovado em 23/abril/2014

Sistema de Avaliação: Double Blind Review 


\title{
RESUMO
}

Este estudo de caso qualitativo objetivou identificar e analisar aspectos relacionados ao processo de aprendizagem de alunos do curso de bacharelado a distância em Administração Pública da Universidade Federal dos Vales do Jequitinhonha e Mucuri - UFVJM. O campo empírico é formado por alunos do Polo de Águas Formosas - MG e os dados foram obtidos por meio de depoimentos em fóruns propostos na plataforma Moodle. Destaca-se que, na visão dos alunos, a leitura é a principal estratégia para a aprendizagem e a internet o principal meio para o acesso às informações. Ademais, as interações com colegas de curso e com os presentes nos demais espaços sociais dos graduandos, com destaque para o ambiente de trabalho, foram citadas como fundamentais para o desencadeamento de reflexões sobre a dualidade teoria-prática suscitando em ressignificações da realidade. Na busca por melhoria do processo de aprendizagem nos cursos a distância, é proposto: (1) melhorar o planejamento e organização do material para a leitura; (2) conhecer o perfil dos alunos; (3) valorizar os grupos formados em torno do curso; (4) reforçar o aproveitamento dos grupos espontâneos; (5) investir em estrutura e tecnologia adequadas; (6) tornar o professor um orientador, centrando no aprendiz o protagonismo da aprendizagem.

Palavras-chave: Aprendizagem. Construtivismo. Ensino a distância.

\begin{abstract}
This case study aimed to identify and analyze aspects related to the learning process of students in bachelor's distance in Public Administration from the Universidade Federal dos Vales do Jequitinhonha e Mucuri - UFVJM. The empirical field is formed by students of the Águas Formosas Polo - MG and data were obtained by means of testimonials on forums proposed in the Moodle platform. It is noteworthy that, in the view of the students, reading is the main strategy for learning and internet the primary means for information access. Furthermore, interactions with classmates and with those present in other social spaces of the students, especially the work environment were cited as fundamental for triggering reflections on the duality theory and practice posing in reinterpretation of reality. In the quest for improving the learning process in distance education, it is proposed: (1) improve the planning and organization of the material for reading, (2) identify the characteristics of students, (3) enhance the groups formed around the course and (4) strengthen the use of spontaneous groups, (5) investing in appropriate infrastructure and technology, (6) make the teacher a mentor, focusing on the role of apprentice learning.
\end{abstract}

Key-words: Learning. Constructivism. Distance learning. 


\section{INTRODUÇÃO}

Por ser considerado como base para o desenvolvimento econômico e social, o estímulo à educação tornou-se a principal estratégia de suporte ao desenvolvimento das nações (Rodrigues, 2004). No entanto, muitos são os gargalos para que educação de qualidade se efetive de forma plena, ampla e democrática. No Brasil, em especial, as desigualdades sociais refletem diretamente na educação, onde a população com maior poder aquisitivo e situada em regiões centrais possui maiores oportunidades de acesso ao ensino de qualidade, ampliando ainda mais as assimetrias de poder entre as classes sociais e entre o "centro" e a "periferia" (CAPES, 2013).

Diante do exposto, o Governo Federal, por intermédio e financiamento da Coordenação de Aperfeiçoamento do Conselho de Pessoal de Nível Superior (CAPES), vem estimulando a implantação de cursos focados em licenciaturas, e, bacharelado e especialização em Administração Pública, na modalidade a distância, para que um número maior de pessoa, sem barreiras geográficas, tenha acesso ao ensino superior e gratuito.

Com o financiamento da CAPES, a Universidade Federal dos Vales do Jequitinhonha e Mucuri (UFVJM), atendendo às demandas da população dos Vales em que atua, oferece três cursos de licenciatura (matemática, química e física) e o curso de bacharelado em Administração Pública na modalidade a distância, este último dentro do Programa Nacional de Formação em Administração Pública - PNAP. Deste modo, a Instituição contribui para que, em onze polos com turmas de 50 alunos (matriculas iniciais), a população regional, distante dos grandes centros, seja contemplada com o ensino de nível superior. Ao adotar esta modalidade educacional, a UFVJM aproveita sua estrutura física e seus recursos humanos (professores e técnicos administrativos) para a extensão do ensino superior a um número maior de interessados.

No entanto, como será abordado na seção posterior, a metodologia de ensino dos cursos a distância $(\mathrm{EaD})$ requer um diferencial comparada aos cursos presenciais, ao ponto de exigir dos docentes e discentes a adoção de novas posturas afim de possibilitar a aprendizagem. Neste processo, o foco se concentra ainda mais no aluno e este entendimento torna-se crucial para que as estratégias de ensino-aprendizagem sejam eficazes.

Deste modo, o professor que atua no ensino a distância necessita de informações que o permita responder aos seguintes questionamentos: como a aprendizagem dos alunos de curso 
de graduação a distância é efetivada?; que fatores atuam como propulsores à aprendizagem neste contexto?.

Dessa forma, delineia-se o objetivo deste artigo, que é identificar e analisar aspectos relacionados ao processo de aprendizagem de alunos do Polo de Águas Formosas - MG que estão cursando o bacharelado em Administração Pública oferecido pela UFVJM na modalidade a distância. As análises têm como pano de fundo as teorias que abordam a aprendizagem como uma construção social, ganhando destaque a experiência, a reflexão e a interação. A noção de experiência extrapola a visão de prática de trabalho, sendo as oportunidades de interação, o contato com materiais instrucionais e momentos de reflexão, mesmo que de forma individual, considerados também como experiências (Mezirow, 1991).

Os dados foram obtidos por meio de depoimentos dos alunos da disciplina de Sociologia Organizacional postados em fóruns propostos na Plataforma Moodle pelo professor da disciplina. Posteriormente, foram analisados de acordo com a orientação da técnica análise do conteúdo (Vergara, 2008).

Para além desta introdução, o artigo segue estruturado com uma revisão bibliográfica abrangendo as temáticas relacionadas à educação a distância e à aprendizagem de adultos; uma terceira seção, onde são apresentados os procedimentos metodológicos adotados; a análise dos resultados obtidos e, por fim, são apresentadas as conclusões do estudo.

\section{ENSINO A DISTÂNCIA}

Como pode ser observado em Freitas e Bertrand (2006), a intensificação do ensino a distância resultou de diversos fatores com destaque para as constantes inovações tecnológicas nos sistemas de comunicação; a intensificação do uso da internet, a crescente busca da população adulta por qualificação, diante da elevada competitividade no mercado de trabalho; e, a dificuldade de acesso físico aos campi universitários, e, de conciliar o estudo com o trabalho e com compromissos familiares e sociais. Assim, a educação superior encontrou no ensino a distância uma grande oportunidade para ampliação de seu campo. Para Fae (2006), os cursos de longa distância têm como principal característica a flexibilidade, tornando os horários de estudos convenientes aos alunos, sem a necessidade de grandes deslocamentos.

Numa perspectiva histórica, Rodrigues (2004) considera que o ensino a distância pode ser caracterizado por cinco gerações. A $\mathbf{1}^{\mathbf{0}}$ geração data do início do século XIX até 1970 e é caracterizada pelo envio do material por correspondência (material impresso e guia de estudos). A $2^{\mathbf{0}}$ geração compreende o período entre os anos 1970 e 1990 com o surgimento 
das primeiras universidades abertas, com design e implementação sistematizados para o EaD (material impresso, transmissões por televisão, fitas de áudio e vídeo, interação alunoprofessor por telefone ou centro de atendimento). A $3^{\circ}$ geração data de 1990 até 2000 utilizando-se de computadores, com recursos multimídia, e de redes de conferência. A $\mathbf{4}^{\mathbf{0}}$ geração data de 2000 até 2005 com o acesso a dados de bibliotecas eletrônicas, aumento da capacidade de processamento dos computadores e da velocidade de transmissão, melhorando a apresentação dos conteúdos programáticos e interferindo na interação entre aluno/professor. Por fim, a $\mathbf{5}^{\mathbf{0}}$ geração se forma a partir de 2005 com a introdução de agentes inteligentes, equipamentos sem fio (wireless) e linhas de transmissão eficientes.

Para Moore e Kearsley (1996, p.1 apud Freitas; Bertrand, 2006), o "conceito de Ensino a Distância é simples: alunos e professores estão separados pela distância e algumas vezes também pelo tempo". Além da separação física entre o aluno e o professor, Freitas e Bertrand (2006) acrescentam o uso de tecnologias de comunicação como base do processo de ensino-aprendizagem e um dos pilares fundamentais para o desenvolvimento do $\mathrm{EaD}$.

\begin{abstract}
Dessa forma, torna-se imprescindível que as organizações que optarem pelo estilo de aprendizagem a distância, em ambiente virtual, desenvolvam estruturas de suporte para a aplicação dos conhecimentos, pois no ambiente virtual não estão contempladas as habilidades e/ou atitudes, características que são desenvolvidas e/ou aperfeiçoadas na prática, principalmente de forma relacional (FAE, 2006).
\end{abstract}

Este formato de ensino permite ao aluno escolher seu próprio ritmo de aprendizagem. Possibilita também, tempo para o aluno refletir sobre as ideias apresentadas, checar anotações e fazer pesquisas. "Tem custo mais baixo, pois não exige computador de última geração nem linhas de transmissão de dados de banda larga" (Freitas; Bertrand, 2006, p. 6).

A forma de comunicação a ser escolhida depende da estrutura e da tecnologia oferecida por cada curso, bem como do tipo de acesso e disponibilidade que cada aluno terá. "Entretanto a utilização de um tipo não exclui o outro" (Freitas; Bertrand, 2006, p. 6). Dentre as principais ferramentas de comunicação, destacam-se:

- Chat ou Bate-Papo. Permite que várias pessoas possam trocar informações de forma síncrona.

- Fórum. Funciona de forma assíncrona. Permite aos participantes acompanhar as mensagens emitidas e recebidas que são organizadas por assunto em um local central. Por funcionar de forma assíncrona, o aluno tem tempo para refletir sobre as questões propostas.

- Correio eletrônico ou e-mail. Também funciona de forma assíncrona. O emissor escreve a mensagem, define o endereço do receptor e a envia pelo correio e, imediatamente, ou após algum tempo, o receptor poderá acessá-la. Esse recurso é importante para a aprendizagem dos alunos porque os colocam em contato imediato, favorecendo a interatividade, a troca de materiais e a produção de textos em conjunto (Freitas; Bertrand, 2006, p. 6). 
Ao comparar a modalidade de ensino a distância com a presencial, Aretio (1996 apud Freitas; Bertrand, 2006) considera que, na modalidade a distância, há uma maior relação do aluno com a organização e sua estrutura, enquanto que no modo presencial a relação professor-aluno é mais íntima. Dessa forma, o ensino a distância requer planejamento cuidadoso, com a implantação de uma estrutura adequada para atender o aluno de forma que este não se sinta solitário no processo. Porém, a intensificação do uso da internet criou condições para que diversas ferramentas fossem desenvolvidas, permitindo o estreitamento da distância entre aluno e professor.

É importante salientar que não se pode, simplesmente, adaptar o ensino presencial para a modalidade a distância. Deve-se desenhar uma nova estrutura organizacional com o objetivo de garantir que o aluno construa sua aprendizagem. Diante da diferença nestas realidades, Aretio (1996 apud Freitas; Bertrand, 2006) alerta que as universidades não podem migrar do ensino da modalidade presencial para a distância sem se reestruturar, caso contrário haverá perda de qualidade do ensino. Evidentemente, é importante para o sucesso do $\mathrm{EaD}$ a adequação de todos os envolvidos: professores, tutores, materiais didáticos, e, estrutura física.

Os professores precisam aprender a atuar como orientadores, instigando os alunos à construção de sua aprendizagem. Freitas e Bertrand (2006) apontam que alunos e professores devem sair do modelo presencial e adotar papéis diferenciados. Por outro lado, os alunos precisam mudar a postura passiva para uma proativa, tornando-se sujeitos de seu aprendizado. Todo o esforço deve ser voltado para os alunos, com a finalidade de apoiá-los, mantendo-os motivados, e, ajudando-os a adequar seus perfis e suas expectativas.

\section{O PROCESSO DE APRENDIZAGEM DE ADULTOS}

A aprendizagem de adultos é compreendida de maneira multifacetada, fazendo com que seus conceitos variem de acordo com a visão de mundo de seus teóricos e com o objeto estudado. No entanto, para Merriam e Caffarella (1999), apesar de ser definida de várias formas, a maioria das definições de aprendizagem inclui os conceitos de mudança de comportamento e experiência.

Em um sentido amplo "a aprendizagem é um processo neural complexo, que leva à construção de memórias" (Fleury; Fleury, 2001, p. 27). Sob um entendimento convencional, Gherardi, Nicoli e Odella (1998, p. 274) afirmam que muitos estudiosos consideram que a aprendizagem ocorre com a internalização de algum tipo de conhecimento por meio da transferência da informação de uma fonte que a possui para o aprendiz. 
No entanto, nesta pesquisa, entendemos a aprendizagem como um processo de construção social, nos embasando nos teóricos que a estudam sob o enfoque construtivista. Esse enfoque considera a aprendizagem como uma atividade cognitiva interna, sendo "um processo de construção de significados por parte do indivíduo" (Merrian; Caffarella, 1999, p. 262).

É importante reconhecer o viés construtivista adotado pela pesquisa, pelo fato de, como foi afirmado por Candy (1991), um pesquisador que considera a aprendizagem como uma questão de dominar uma porção estável de fatos provavelmente adotará uma abordagem substancialmente diferente para a pesquisa daquele que a vê como uma interação dinâmica entre um educando e um mundo em constante mudança.

Sob este entendimento da aprendizagem, os seres humanos são tidos como agentes orientados por metas, buscando feedbacks. Assim, o processo de aprendizagem individual é determinado pelas necessidades, intenções, expectativas, e feedbacks percebidos pelo indivíduo (Lehesvirta, 2004). Os aprendizes não são seres passivos que respondem aos "estímulos", e a aprendizagem não é meramente a apropriação de rótulos e categorias previamente desenvolvidas. A aprendizagem é um processo ativo de construir o significado e transformar a compreensão (Candy, 1991).

Em decorrência, para nós, assim como foi exposto por Freire (1996, p. 69, grifos do autor), "aprender é "construir, reconstruir, constatar para mudar" sendo necessária uma abertura do espírito do indivíduo". A interação entre as pessoas é uma interação onde todos os envolvidos são sujeitos, todos ensinam e todos aprendem.

Outra teoria que deu grande contribuição para o entendimento da abordagem construtivista é a "biologia do conhecer" desenvolvida por Maturana e Varela ao proporem que "os seres vivos se caracterizam por - literalmente - produzirem de modo contínuo a si próprios, o que indicamos quando chamamos a organização que os define de organização autopoiética" (Maturana; Varela, 2003, p. 52).

Para Moura (2005, p. 9, grifos do autor), a biologia do conhecer faz uma crítica ao "paradigma representacionista da realidade, colocando-se entre realismo e idealismo para propor, em sua 'contabilidade lógica', que o mundo não é uma experiência separada da experiência do indivíduo, ou seja, que a estrutura humana torna possível um mundo".

Portanto, para a biologia do conhecer, aquilo que nos afeta é determinado por nossos domínios estruturais. Nossa aprendizagem depende muito mais de nossas estruturas internas que dos estímulos do ambiente. 
Cada pessoa diz o que diz ou ouve o que ouve segundo sua própria determinação estrutural. Da perspectiva de um observador, sempre há ambiguidades numa interação comunicativa. O fenômeno da comunicação não depende daquilo que se entrega, mas do que acontece com o receptor. E isso é um assunto muito diferente de transmitir informação (Maturana; Varela, 2003, p. 218).

A construção do conhecimento se dá na relação, em meio às perturbações recíprocas que marcam a vida associada, e que desencadeiam processos internos (questionamento, reflexão, dúvida, reconcepção), mas não como uma informação que vai de um a outro. Não ouvimos o que o outro diz, mas o que somos estruturalmente capazes de ouvir; não vemos o que o outro vê, tampouco vemos a realidade, o mundo, mas conhecemos uma realidade e um mundo no ver e no ouvir (e, sobretudo, no emocionar), de acordo com o que nossa estrutura permite (Moura, 2005, p. 12).

Mezirow (1991) também considera a aprendizagem como dependente das estruturas internas dos indivíduos. Para ele, aprender nada mais é que usar um sentido que nós já tenhamos construído para guiar a maneira como pensamos, agimos, ou sentimos sobre o que estamos experimentando. O significado é que dá coerência às nossas experiências.

Este autor (1991) descreve o processo de aprendizagem composto por etapas como a esquematização, que é fazer uma associação dentro de uma estrutura de referência; $\underline{\text { adequação, }}$ que é aceitar uma interpretação como sua (própria); lembrar, que é apelar para uma interpretação anterior; validação, que é estabelecer a verdade, justificativa, adequação, ou autenticidade do que é declarado; e ação, que é decidir, mudar uma atitude para com, modificar a perspectiva sobre, ou desempenhar alguns aspectos de nosso envolvimento com o ambiente, outras pessoas, ou nós mesmos. "O aprendizado sempre envolve tornar uma nova experiência explícita e esquematizá-la, adequá-la, e agir sobre ela” (Mezirow, 1991, p. 4).

Assim, o indivíduo, para aprender, ajusta a nova informação ao que ele já sabe. O indivíduo não aprende as coisas como tais, mas sempre em contextos situacionais e relacionados à sua motivação, atividade e experiências anteriores. As crenças, emoções, sentimentos e atitude do aprendiz, assim como o ambiente, a cultura e o clima afetam fortemente o processo de aprendizagem (Lehesvirta, 2004).

Em decorrência, para Merriam e Caffarela (1999), ensinar na perspectiva construtivista envolve fornecer experiências que induzam ao conflito cognitivo e, portanto, que encoraje os aprendizes a desenvolver novos esquemas do conhecimento que sejam melhores adaptados à experiência. Por outro lado, para Freire (1996, p. 22, grifo do autor) é preciso que o "formando, desde o princípio mesmo de sua experiência formadora, assumindose como sujeito também da produção do saber, se convença definitivamente de que ensinar não é transferir conhecimento, mas criar as possibilidades para a sua produção ou sua construção". 
Observa-se, então, que as perspectivas construtivistas, com destaque para a Biologia do Conhecer, têm como foco a dependência da estrutura interna dos indivíduos para a aprendizagem. No entanto, mesmo dada a importância das estruturas internas do sujeito para a construção do conhecimento, não desconsideramos a influência do contexto social para o desenvolvimento do mesmo. Apenas não aceitamos a noção de "transmissão" de conhecimento pronto e acabado de um educador para o aprendiz, e sim a aprendizagem em uma prática situada em um contexto social, tendo como variáveis relevantes para a sua efetividade as expectativas e estruturas internas dos aprendizes e as interações que tornam possível o entendimento entre os mesmos.

Dentre as teorias que têm uma abordagem construtivista se destacam as que consideram a aprendizagem como um processo de reinterpretação das experiências, de reflexão sobre a prática, e, como um processo situado num contexto social.

\subsection{A APRENDIZAGEM COMO UM PROCESSO DE REINTERPRETAÇÃO E REFLEXÃO SOBRE A EXPERIÊNCIA}

Alguns pesquisadores que estudam a aprendizagem de adultos consideram que aprender é dar novos significados às experiências (Kolb, 1976; Jarvis, 1987; Mezirow, 1991). Esta abordagem, segundo Merriam e Caffarella (1999) considera que a experiência assume o papel principal na aprendizagem. A experiência é tanto como um recurso quanto um estímulo para a aprendizagem.

Nesta perspectiva, a aprendizagem é um processo dialético de interpretação no qual interagimos com os objetos e eventos, guiados por um conjunto antigo de expectativas. Quando aprendemos algo, atribuímos um antigo sentido a uma nova experiência. Em outras palavras, usamos expectativas estabelecidas para explicar e construir o que percebemos ser a natureza de uma faceta da experiência que até aqui tem carecido de clareza ou tem sido mal interpretada. Desse modo, a aprendizagem é compreendida "com o processo de usar a interpretação nova ou revisada do sentido da experiência de alguém a fim de guiar para a ação futura" (Mezirow, 1991, p. 12).

$\mathrm{Na}$ visão Kolb (1976), os profissionais para serem bem sucedidos necessitam desenvolver a habilidade de explorar oportunidades novas e de aprender com os sucessos e falhas passadas. Ainda Kolb (1976), a aprendizagem é compreendida como um ciclo de quatro estágios: experiência concreta, estágio em que torna-se necessário a abertura e vontade das pessoas para se envolverem em novas experiências; observação reflexiva, 
demandando que as pessoas vejam as novas experiências a partir de uma variedade de perspectivas; abstração de conceitos, sendo necessária uma análise que possibilita a criação de conceitos e ideias a partir da observação; e, experimentação ativa, onde as pessoas tomam decisões e resolvem problemas permitindo a utilização das novas ideias e conceitos na prática.

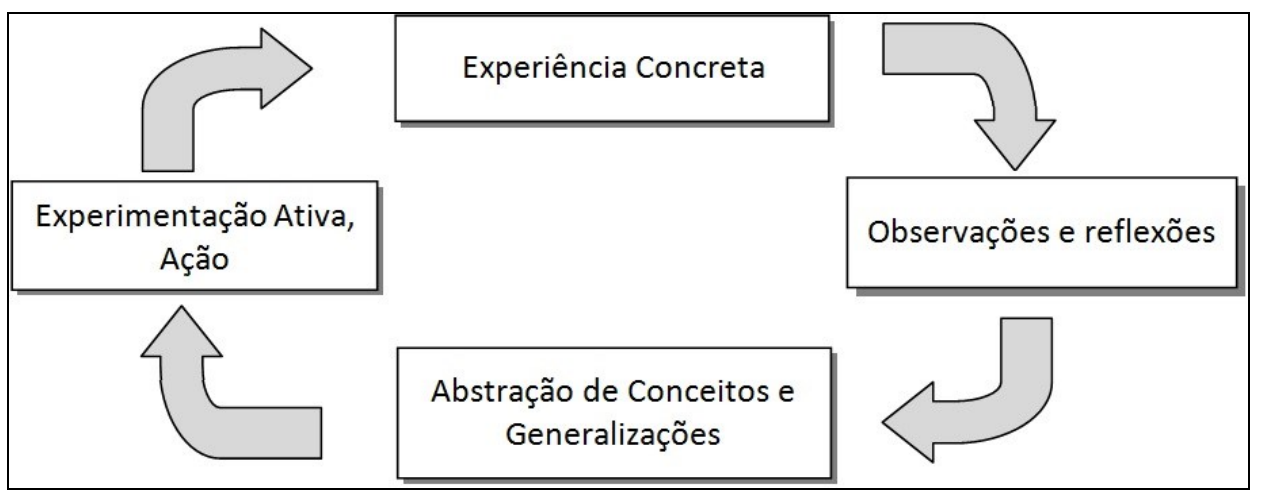

Figura 1 O Modelo de Aprendizagem Experiencial Fonte: Kolb, 1976, p. 22.

Estes estágios formam um processo contínuo de aprendizagem onde as experiências concretas dos sujeitos servem de base para a observação e para a reflexão. Destas observações são formadas abstrações de conceitos e generalizações que são testadas através da experimentação ativa em novas situações, construindo novos conhecimentos e recomeçando o ciclo a partir de novas experiências.

Jarvis (1987) também considera que a aprendizagem começa com a experiência, sendo a primeira um processo de transformação da experiência em conhecimentos, habilidades e atitudes. As experiências ocorrem por todo o processo de existência, onde quer que haja vida, há experiências potenciais de aprendizagem. Essas experiências podem ser naturais ou "artificialmente criadas, apreendida por alguém ou qualquer combinação dos sentidos, o próprio processo de pensar, uma situação específica ou ideias abstratas, e podem ser significativas ou sem significado" (Jarvis, 1987, p. 1).

Para Jarvis (1987) a experiência envolve a relação entre pessoas e os arredores onde elas vivem, de forma que a aprendizagem é sociocultural e acontece em um tempo, passando a ser temporal-sócio-cultural. Para ele, é dentro deste contexto que as pessoas desenvolvem conhecimentos, habilidades e atitudes.

Desse modo, nenhuma experiência ocorre de maneira isolada. Consequentemente, para compreendê-la, além das análises psicológicas, tornam-se necessárias as análises sociológicas. "As experiências significativas e as sem sentido ocorrem em situações sociais, ou no mínimo 
de modo socialmente modelado, e é a esses fenômenos que essa análise é endereçada" (Jarvis, 1987, p. 2).

Jarvis (1987) complementa o trabalho de Kolb ao considerar que nem toda experiência é significativa, algumas são sem significado. Para ele são as pessoas que dão sentido às experiências. Em uma mesma situação socio-cultural-temporal as pessoas têm diferentes interpretações da situação. Isso se dá pelo fato de que as pessoas trazem uma constelação de experiências prévias para cada situação. Então, as pessoas têm backgrounds que fornecem significados a suas experiências que possibilitam a aprendizagem. Caso o estoque de conhecimento seja inadequado, suas experiências podem ser de pouco, ou nenhum sentido e, consequentemente, ocorrerá pouca aprendizagem.

A necessidade de aprender ocorre quando há uma consciência da deficiência no estoque de conhecimento. O indivíduo tem uma nova experiência, mas o seu estoque de conhecimento não é capaz de produzir uma resposta automática. Em outras palavras, quando há uma disjunção entre o estoque de conhecimento do indivíduo e suas percepções do mundo sócio-cultural-temporal de suas experiências, surge uma potencial aprendizagem pela experiência. Mas, para que esta experiência se torne significativa, é necessário que haja reflexão sobre ela. Caso contrário, a ação pode ser tomada como certa e pouca ou nenhuma aprendizagem ocorre (Jarvis, 1987).

Ao complementar o modelo de Kolb (1976), Jarvis (1987) propõe o seguinte modelo:

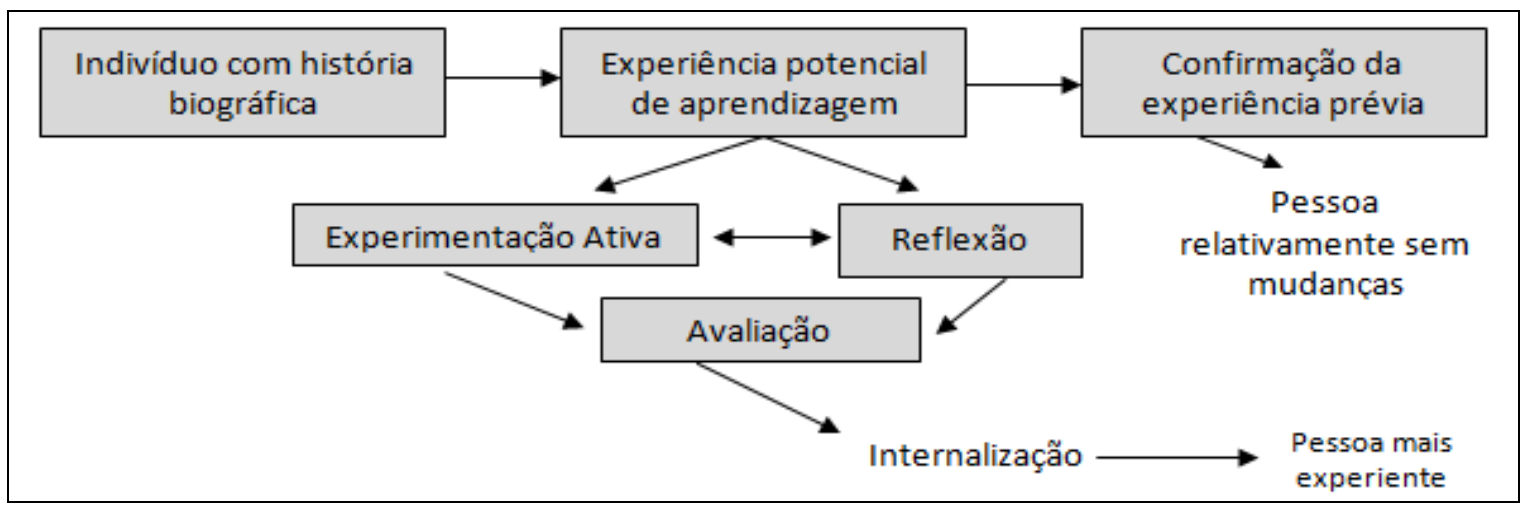

Figura 2 Modelo Revisado do Processo de Aprendizagem.

Fonte: Jarvis, 1987, p. 166.

Dewey (1979) também destacou a importância da experiência para a aprendizagem. No entanto, para ele, assim como foi exposto por Jarvis (1987), nem todas as experiências são genuínas e educativas. Algumas podem não ser educativas, podendo parar ou distorcer o crescimento para experiências posteriores. Em decorrência, a aprendizagem depende da 
qualidade da experiência no aspecto imediato, ao ser agradável ou desagradável, e no aspecto mediato, ao se relacionar às experiências posteriores, tornando-se um problema para o educando fazendo com que o mesmo influa de forma útil e criativa nas experiências posteriores.

Outro ponto relevante citado por Dewey (1979) é a expressão da continuidade e da interação como dois princípios fundamentais da experiência em sua função e sua força educativa. Esses dois princípios se interceptam e se unem. A continuidade significa que toda e qualquer experiência utiliza algo das experiências anteriores que modifica, de algum modo, as experiências posteriores. A qualidade da experiência, entretanto, é que vai influenciar o "modo" que o princípio da continuidade se aplica. Assim, quando uma experiência desperta curiosidade, ela fortalece a iniciativa e suscita desejos e propósitos suficientemente intensos para conduzir uma pessoa aonde for preciso fazendo com que a continuidade funcione. Por sua vez, o princípio da interação, diz respeito à ligação existente entre o meio ambiente e o indivíduo. Uma experiência é resultado de uma transação que está ocorrendo entre um indivíduo e o seu meio. Desse modo, toda experiência humana é social, ou seja, envolve contato e comunicação entre indivíduos.

\subsection{A APRENDIZAGEM NO CONTEXTO SOCIAL}

Sob a orientação de que aprendizagem é situada e influenciada por um determinado contexto, Lave e Wenger (1991) ao tentarem esclarecer o conceito de aprendizagem situada reforçam a concepção de que a aprendizagem é inseparável da prática social. Esta abordagem apresenta a ideia de que a prática social vem primeiro e a aprendizagem é uma de suas características. A teoria da prática social enfatiza a relativa interdependência do indivíduo e mundo, atividade, significado, cognição, aprendizagem e conhecimento. Essa visão sustenta que aprendizagem, pensamento e conhecimento são relações entre pessoas em atividade no mundo socio-culturalmente constituído.

$\mathrm{Na}$ aprendizagem situada se destacam dois conceitos principais que são a "participação periférica legítima" e as "comunidades de prática".

A participação periférica legítima é o processo por meio do qual os aprendizes se tornam membros completos e obtêm legitimação através da participação na prática sóciocultural da comunidade. Isto é, o aprendiz busca sua participação de forma legitimada por meio da ajuda de membros mais experientes da comunidade. No entanto, a participação 
periférica legítima provê mais do que a "observação"; envolve também a "participação" como uma forma de aprendizado da "cultura da prática" (Lave; Wenger, 1991).

A participação legítima não é apenas uma condição crucial para a aprendizagem, mas um elemento que a constitui, bem como a participação periférica refere-se a se localizar no mundo social, uma noção complexa que implica em estruturas sociais envolvendo relações de poder (Lave; Wenger, 1991).

Assim, para Gherardi, Nicolini e Odella (1998) aprender requer o acesso e a oportunidade de fazer parte na prática usual de um grupo, sendo também uma forma de empowerment. A aprendizagem envolve a estrutura social, relações de poder e legitimação, resultado da participação no ambiente e na prática cultural em que o conhecimento é construído.

Como aprender, pensar e saber são relações entre pessoas em um mundo social e culturalmente estruturado, para Gherardi, Nicolini e Odella (1998), a aprendizagem se dá por meio das comunidades de prática, onde a prática é dependente dos processos sociais através dos quais é sustentada e perpetuada, e aprender ocorre com o acoplamento nessa prática.

A comunidade de prática não implica necessariamente em um grupo bem definido ou fronteiras da comunidade socialmente visíveis; implica participação em um sistema de atividades no qual os participantes compartilham entendimentos sobre o que estão fazendo e o que isto significa em suas vidas e para suas comunidades (Lave; Wenger, 1991).

O conceito de comunidades de prática contrasta com a visão dominante na nossa sociedade em que a aprendizagem ainda é vista como um processo de "entrega de conhecimento", isto é, baseada na noção de aprendizagem como um processo de entrega de informação proveniente de uma fonte de conhecimento (professor ou livro) para um alvo carente desta informação.

Nesta última visão, aprendizagem equivale essencialmente à aquisição de um conjunto de dados e fatos, que são acumulados por todas as gerações que nos precederam. Esse conhecimento é "externo", e está armazenado em alguma memória (documentos, livros), sendo que o principal esforço do aprendiz é adquiri-lo e armazená-lo na sua própria mente para utilizá-lo quando necessário.

Adotar a perspectiva social da aprendizagem significa focar os processos de participação e interação que servem de base ao próprio contexto para a aprendizagem. Nesse novo cenário a linguagem assume importância central e é concebida como a principal forma 
de ação no mundo social, em vez de ser meramente entendida como um mediador da transmissão de conhecimento (Gherardi, Nicolini; Odela, 1998).

\section{PROCEDIMENTOS METODOLÓGICOS}

Nesta pesquisa foi adotada uma abordagem qualitativa ao buscar compreender a aprendizagem de alunos por meio da educação a distância analisando as nuanças desse processo, sem a mínima intenção de gerar dados quantificáveis e/ou generalizáveis a outros contextos. Trata-se também de um estudo descritivo apresentando de maneira detalhada o fenômeno social que o envolve (Godoy, 2006).

A etapa inicial do estudo foi constituída por revisão teórica, que trouxeram informações relevantes para o estudo da educação a distância e do processo de aprendizagem de adultos sob ótica construtivista. O campo empírico é formado por alunos do curso de Graduação em Administração Pública do Polo de Águas Formosas - MG vinculado à Universidade Federal dos Vales do Jequitinhonha e Mucuri - UFVJM, tratando-se desde modo de um estudo de caso, conforme Yin (2001). Os dados foram obtidos por meio de depoimentos dos alunos sobre a temática abordada postados na Plataforma Moodle em quatro fóruns propostos pelo professor da disciplina de Sociologia Organizacional, oferecida no terceiro período do curso (entre novembro de 2012 e março de 2013). Dos 34 alunos matriculados e com participação frequente na disciplina, foram obtidos depoimentos de 27 alunos no primeiro fórum de debate, de 31 no segundo, de 26 no terceiro e de 23 no quarto. Para preservar a identidade dos alunos, seus nomes foram substituídos por pseudônimos.

As questões principais que nortearam os debates nos quatro fóruns foram, respectivamente: como você está aprendendo os conteúdos trabalhados no curso de Administração Pública a distância?; seus colegas de Polo contribuem para a aprendizagem dos conteúdos trabalhados no Curso?; caso afirmativo, de que forma?; qual a importância do seu meio social na aprendizagem dos conteúdos trabalhados no Curso?; você acha que sua experiência prévia contribui para a aprendizagem dos conteúdos abordados no Curso?

A partir dos depoimentos dos graduandos, os dados foram analisados em consonância com a proposta da análise de conteúdo (Vergara, 2008). Após o agrupamento das respostas, foram identificadas categorias comuns a cada depoimento que, posteriormente, foram agrupadas e analisadas à luz do referencial teórico aqui exposto, para que, finalmente fossem tecidas algumas considerações finais. 


\section{RESULTADOS}

\subsection{A APRENDIZAGEM A DISTÂNCIA NA VISÃO DOS GRADUANDOS}

Corroborando com o referencial utilizado sobre o EaD, os alunos participantes dos fóruns enfatizaram que a leitura é a principal prática para a construção da aprendizagem. Como pode ser observado nos depoimentos a seguir, destacam-se como materiais utilizados para a leitura as apostilas, os textos fornecidos pelos professores por meio da plataforma Moodle e os adquiridos por meio da internet.

Bem, o método que tenho utilizado para aprender é o que o próprio curso me fornece. As leituras, as atividades, as ferramentas disponíveis, as aulas presenciais e, quando necessário, pesquisas em internet, pois a biblioteca que temos aqui na cidade não atende a demanda para cursos superiores (Danilo, participação no $1^{\circ}$ fórum). Eu busco aprender os conteúdos trabalhados no curso de Administração Pública por meio de leituras constantes e entrega dos trabalhos dentro dos prazos estipulados (...) (Marta, participação no $1^{\circ}$ fórum).

Como podemos observar em Kolb (1976), Jarvis (1987) e Mezirow (1991), a leitura permite ao aluno uma nova experiência por meio da qual este utiliza seu background para interpretar as informações que passam a ter contato e fazer ajustamentos entre esta experiência e sua antiga visão de mundo, fruto de experiências passadas. Torna-se crucial neste processo, diante das expectativas do aprendiz, que o material utilizado tenha significado para mesmo, instigando reflexões. Neste sentido, como apontado por Cláudia, em depoimento dado no $1^{\circ}$ fórum, a prática de exercício, possibilita ao aluno "pairar mediativamente" sobre o assunto abordado dando significação ou resignificação ao mesmo.

Por vivenciarem um período posterior à quinta geração do Ensino a Distância (Rodrigues, 2004) e pelas limitações estruturais do Polo de ensino, com um número insuficiente de obras na biblioteca local, é a internet o principal canal utilizado pelos alunos para o acesso às informações. A internet não permite apenas o contato com artigos, textos, livros digitais, vídeos, dentre outros, mas também possibilita a comunicação e contato entre os sujeitos principais do processo de aprendizagem: tutores, professores e colegas de curso.

Como a leitura requer tempo e dedicação, uma das principais barreiras à aprendizagem destacada pelos alunos é fato deles terem outras prioridades, além do estudo. A aluna Regina, em depoimento no primeiro fórum, afirma que na modalidade a distância, é exigido muito "mais disciplina do estudante para poder conciliar tempo, que às vezes é escasso durante o dia. Mas tenho procurado organizar o meu tempo e tirado um espaço na minha noite só para os estudos". 
Em decorrência, uma das estratégias adotadas por parte dos graduandos foi a formação de grupos de estudos. Por meio deles, tornou-se possível a interação para troca de informações e apoio mútuo. Como é apontado por Lave e Wenger (1991) e Gherardi, Nicolini e Odella (1998), a aprendizagem como fruto de uma prática social requer a constituição de comunidades, e em períodos iniciais do curso, como pode ser observado no depoimento da Joseane (participante do primeiro fórum), os alunos sentiram dificuldades para a interação, impactando fortemente na aprendizagem.

Nos dois primeiros períodos do curso observei que não houve muita interação entre nós no sentido de nos ajudarmos no esclarecimento de dúvidas ou mesmo para enriquecimento de conhecimento, principalmente da minha parte que praticamente não interagi com os meus colegas por diversos fatores como tempo disponível e distância, por exemplo.

No entanto, ultrapassada a fase de isolamento inicial, com os encontros presenciais, avaliações, web conferências, reuniões para estudo e desenvolvimento de trabalhos em grupo, a comunidade tomou corpo, ampliando as interações. O depoimento de Sandra (participante do $1^{\text {o }}$ fórum) ilustra tal observação: "o que me ajuda muito na aprendizagem é a interação com colegas, pois vamos reunindo o que cada um conseguiu absorver e aos poucos montamos nosso aprendizado, isso vem sendo evidenciado a cada semestre". Apesar desta fala dar a entender que esta aprendizagem social se efetiva por meio de uma convergência entre as percepções, o aluno Mágno (participação no $1^{\circ}$ fórum), esclarece que mais enriquecedor ainda são as divergências entre os membros do grupo: "os trabalhos e os estudos em grupo são interessantes porque são expostas as nossas divergências. Vejo como essencial o companheirismo e a cooperação entre os colegas".

A estratégia de se associarem em grupos de estudos, além de surtir grande efeito na aprendizagem, surge como alternativa diante da pouca interação face a face entre professor e aluno. Deste modo, apesar da relevância do grupo, modos de comunicação alternativos (Freitas; Bertrand, 2006) entre professores e alunos, foram considerados como essenciais.

De manhã, meio dia e à noite, sempre passo para ver as novidades no Moodle. A comunicação com tutores, professores e alunos tem melhorado muito. Dúvidas técnicas, prazo de entrega de trabalhos, dia de aula presencial, todas essas dúvidas são tiradas pelos meios de comunicação, ambiente virtual e até mesmo pelo celular. Essa interação tem facilitado o aprendizado (Carlos, participação no $1^{\circ}$ fórum).

Por outro lado, apesar das alternativas citadas para a comunicação e interação entre aluno e professor, a aluna Cláudia (participação no primeiro fórum) acredita que está "absorvendo as informações de forma mais lenta do que com o método presencial, pois o 
contato com o professor é enriquecedor". Para ela, as explicações ampliam a "visão e indicam uma direção correta a seguir, enquanto que no curso a distância, existe uma incerteza sobre o caminho para melhor entendimento e compreensão do que é apresentado". Diante do exposto, foi apontado que os encontros presenciais e as web aulas surtem grande impacto na facilitação da aprendizagem dos alunos.

Apesar dos alunos terem consciência de serem os principais protagonistas de sua aprendizagem, observa-se por parte deles uma expectativa quanto a um direcionamento do professor em relação ao que deve ser estudado, amenizando a angústia e insegurança que enfrentam. Podemos observar, pela pragmática da linguagem por trás dos depoimentos, que a todo o momento os alunos colocam o ensino presencial como superior ao a distância que, na visão deles, deve ser adotado quando não se tem alternativa. Deste modo, observamos uma atribuição muito maior aos fatores exógenos que aos endógenos aos indivíduos como definidores da aprendizagem. Esta percepção pode se tornar uma barreira restritiva à aprendizagem uma vez que as expectativas agem diretamente sobre a motivação e comportamento voltado para construção do conhecimento do aprendiz (Lehesvirta, 2004).

Em grande parte dos depoimentos, observamos uma compreensão por parte dos alunos de que existe um caminho correto para a maximização da aprendizagem e em poucos é observado que há uma consciência da necessidade de autonomia do aluno e construção do próprio caminho diante de suas estruturas mentais e possibilidades de acoplamento ao seu meio social (Maturana; Varela, 2003). Seria interessante que os demais alunos corroborassem com a visão da aluna Clariana (depoimento no primeiro fórum) ao argumentar que: "não existe fórmula mágica. É necessário motivação para abrirmos mão do tempo livre, dos filmes, das telenovelas, em prol de um objetivo maior. Dedicação nos finais de semana e feriados". Para ela, a maior dificuldade está na "disciplina" para os estudos.

\subsection{A IMPORTÂNCIA DO CONTEXTO SOCIAL}

Como foi observado anteriormente, nesta pesquisa, assim como no referencial teórico adotado, observamos uma grande importância dada às interações para que a aprendizagem seja facilitada. Com o distanciamento espacial entre professores e alunos, os graduandos consideraram como de grande relevância as interações entre colegas.

A interatividade é algo essencial na vida do ser humano. Acredito que para o processo de ensino aprendizagem a interação é algo que nos permite aprender, compartilhar e aprimorar conhecimentos. Apesar da distância e da correria diária, esta comunicação que tenho com meus colegas de polo, seja no momento de dúvida, 
de ajuda, por meio de uma conversa, um telefonema, grupo de estudo..., está me ajudando bastante. A minha aprendizagem depende da minha dedicação, esforço, do professor..., contudo, meus colegas também fazem parte desta conquista; portanto, também é por meio deles que venho aprendendo a superar desafios que alguns conteúdos me trazem (Regina, participação no $2^{\circ}$ fórum).

No entanto, como foi afirmado pelo aluno Carlos, em depoimento dado no segundo fórum, a interação não se restringe à presença física, ou contato face a face. Os fóruns de discussões e os trabalhos da plataforma de ensino possibilitam o acesso à forma de pensar de cada colega. "Esse conhecimento é adquirido em fontes de informação diferentes, livros, páginas de internet e conhecimento empírico e que vai nos auxiliar muito como futuros administradores públicos". "E é nessa troca de conhecimento é que vamos aprendendo, sempre ligando para o colega, contando sobre o vencimento da próxima atividade avaliativa, sobre a dificuldade de acessar determinado conteúdo. Com isso, um estimula o outro a não desistir" (Carlos, participação no $2^{\circ}$ fórum).

Observamos que as interações vão além do compartilhamento de informações, são também responsáveis pela construção da identidade do grupo. Ao sentir como parte de um grupo, o aluno se sente fortalecido ao se conscientizar de que os problemas que enfrenta são comuns a todos e isto fortalece a sua disposição para a continuidade no curso. A aluna Edilane (participação no $2^{\circ}$ fórum) afirma que: “sem o incentivo dos meus colegas já teria desistido. É muito importante essa interatividade, na verdade alguns assuntos são compreendidos por uns e por outros não, por isso a importância do contato, do grupo e do debate". Clariana (participação no $2^{\circ}$ fórum) complementa que: "há uma cumplicidade na turma que é realmente cativante, que nos ajuda não apenas na realização dos exercícios, fixação de atividades e ou compreensão de alguma matéria, mas principalmente nos ajudando a superar os desafios".

Além das interações com colegas de cursos, outro ponto destacado pelos alunos foi a interação com as demais pessoas do ambiente familiar ou de trabalho. Como pode ser observado nas falas abaixo, o meio social torna-se relevante a partir do momento que possibilita associação e/ou disjunções entre teoria e prática. Deste modo, o meio social possibilita conflitos cognitivos, desencadeando em reflexão e novas resignificações da realidade. Compreensões sobre a cultura local em comparação com outras culturas, com destaque para seus valores, objetivos e tecnologias, possibilitam a construção de maior criticidade sobre o que está sendo feito e como pode ser melhorado.

O meu meio social é importante para a minha aprendizagem como acadêmica do curso Bacharelado em Administração Pública uma vez que a partir das experiências vividas principalmente em meu local de trabalho (prefeitura) analiso nossos gestores 
públicos e suas práticas e faço um comparativo entre a realidade e aquilo que seria o ideal e a partir daí vou assimilando os conteúdos trabalhados no curso (Joseane, participação no $3^{\circ}$ fórum).

O nosso meio social contribui para nortearmos melhor os conteúdos estudados no curso de Administração Pública. Estudamos a parte teórica no curso, e esse conhecimento é comparado com a nossa convivência no nosso dia-a-dia, sendo entendido e fixado de acordo nosso contexto social. Deste modo, podemos assimilar e diferenciar o certo do errado, comparando a realidade com as boas práticas de administração pública até então estudadas no curso. No entanto, cada discente está inserido em uma realidade diferente, realidade essa que poderá favorecer o entendimento do conteúdo estudado, de acordo as especificidades vivenciadas (Carlos, participação no $3^{\circ}$ fórum).

No entanto, como foi apontado por Dewey (1979) e Jarvis (1987), na visão do aluno Mágno, em depoimento postado no terceiro fórum, o contexto social também pode possibilitar condições que restringem a aprendizagem. Isto se dá pelo fato deles já terem uma vivência na área podendo implicar em interpretações equivocadas do conteúdo abordado, caso não haja abertura para um novo entendimento sobre esta experiência.

\subsection{A IMPORTÂNCIA DA EXPERIÊNCIA PRÉVIA}

Por fim, em relação às experiências prévias, os alunos as consideraram como direcionadoras da interpretação dos assuntos trabalhados no curso. Como o aluno Antônio Carlos (participação no $4^{\circ}$ fórum) afirmou, "para prosseguir num curso desse nível, é necessário que se tenha um pré-requisito de conhecimentos múltiplos, senão ficaria difícil assimilar os assuntos abordados". "Os assuntos abordados complementam aqueles que assimilamos nas nossas experiências prévias, sistematizando-os e isso contribui para a aprendizagem" (Regina, participação no $4^{\circ}$ fórum). "Por meio dos assuntos abordados posso analisar as minhas experiências e aperfeiçoar meu ponto de vista. E para o processo de construção da minha formação profissional esta análise é bastante proveitosa" (Regina, participação no $4^{\mathrm{o}}$ fórum).

Como a aprendizagem impacta diretamente na mudança de comportamento, as associações feitas pelos alunos entre os temas trabalhados nas disciplinas do curso e suas ações naquele momento específico possibilitam a construção de backgrounds, subsidiando novos direcionamentos. Esta aprendizagem extrapola as questões relacionadas à gestão pública, indo às questões relacionadas à família, trabalho e relações interpessoais, ampliando a percepção do aluno de modo geral (Kolb, 1976; Jarvis, 1987; Mezirow, 1991).

Como apontado pelo Carlos (participação no $4^{\mathrm{o}}$ fórum), as reflexões permitem interpretações de questões que se deparam no presente, ou, que se depararão no futuro, e, também possibilita novos entendimentos sobre fatos passados, permitindo reinterpretá-los. 
"Os assuntos abordados retratam a realidade da maioria dos discentes, pois todos ou quase todos já atuam na administração pública”.

É observado que neste processo há um ciclo de mão dupla, sendo que "os assuntos abordados no curso contribuem para uma melhor reflexão a respeito do cotidiano e em contrapartida, a prática do trabalho facilita o entendimento" (Maria de Lourdes, participação no $4^{\mathrm{o}}$ fórum) dos conteúdos trabalhados.

É neste processo que a interpretação do que venha a ser certo ou errado se altera. "Logo, a experiência prévia ajuda na aprendizagem, além de ser uma ótima oportunidades de corrigir erros, que julgávamos serem corretos” (Eliza, participação no $4^{\circ}$ fórum).

Uma vez que temos a oportunidade de nos libertar de conceitos limitadores e que impedem um maior entendimento e compreensão do ambiente que nos cerca e do qual somos parte integrante, e passamos a ser dotados de competência modificadora quando nossos horizontes são alargados por meio do conhecimento que ultrapassa limites e fronteiras (Marta, participação no $4^{\circ}$ fórum).

\section{CONSIDERAÇÕES FINAIS}

Na busca por respostas para as questões propostas nesta pesquisa quanto à forma que a aprendizagem dos alunos de cursos de graduação a distância está sendo efetivada, e, sobre que fatores atuam como propulsores à aprendizagem neste contexto, observamos que os depoimentos confirmam grande parte das informações presentes no referencial teórico, porém amplia a compreensão da aprendizagem no campo específico do $\mathrm{EaD}$.

Cabe destacar a leitura como a base para aprendizagem e a internet como forma de acesso aos conteúdos trabalhados e interação entre alunos, tutores e professores. Este aspecto identificado serve de alerta aos coordenadores/professores das disciplinas oferecidas na modalidade a distância quanto a importância do planejamento e organização do material para a leitura. Como há pouca proximidade entre os sujeitos, a forma como a disciplina é estruturada poderá despertar ou não o interesse do aluno em aprofundar a leitura utilizando suas estruturas internas para darem significação ao conteúdo. Conhecer o perfil dos alunos também passa a ser relevante, o que justifica a manutenção de encontros presenciais em cada polo, de preferência no início de cada semestre. Outro fator diretamente atrelado a esta realidade, que na visão dos alunos atrapalha o processo de aprendizagem é estrutura inadequada da biblioteca do polo de apoio. Apesar de a internet possibilitar o acesso a uma diversidade de informações, alguns materiais específicos só podem ser acessados caso constem como exemplares na biblioteca local. 
Nota-se ainda que os grupos formados em torno do curso podem ser considerados como embriões de comunidades de prática (Lave; Wenger, 1991) na medida em que os estudantes se aproximam sem hierarquias (pelo menos formais) na busca por aprendizagem. É essa interação que permite a troca de ideias, experiências, reflexões em grupo e a formação da identidade do grupo. Desta forma, estes espaços podem e devem ser reforçados pelos professores das disciplinas no sentido de aproveitar estes grupos espontâneos.

É nessa questão de possibilitar a informação e interatividade que chamamos a atenção para outro ponto de grande relevância e que também está relacionado à estrutura, que é o investimento em tecnologia de informação. Os fóruns, web aulas, web conferências só se tornam possíveis caso a universidade invista em tecnologias que permitam o uso dessas ferramentas a contento. Apesar de não ser o foco desse caso de estudo, em alguns depoimentos a deficiência desses recursos (principalmente relacionada à conectividade) foi indicada como um dos principais gargalos à interação entre professores e alunos.

Deste modo, apesar de ser considerado de baixo custo (Freitas; Bertrand, 2006), deve ser tomado o cuidado com o fato de que investimentos e adequações estruturais apropriadas ao ensino a distância serem necessárias. Caso contrário, a adoção desta modalidade de ensino pode se tornar apenas uma estratégia para se ampliar o número de alunos sem que a estes seja dada a possibilidade de ensino de qualidade. Ao considerarmos que no $\mathrm{EaD}$ o foco da aprendizagem se concentra ainda mais no aluno, não descartamos o papel da instituição de ensino em criar condições para que a aprendizagem seja facilitada. Caso contrário, estaríamos retrocedendo às primeiras gerações do $\mathrm{EaD}$, como no caso do ensino por correspondência.

A experiência, amplamente destacada pelos teóricos da aprendizagem, foi considerada como fator propulsor para a aprendizagem, uma vez que é por meio dela que os alunos compreendem os assuntos tratados e constroem nova visão de mundo. Esta constatação pode subsidiar o debate sobre a necessidade da inserção de Estágio Supervisionado na grade dos projetos pedagógicos do curso de Administração Pública a distância. Ao nos basearmos na importância dada pelos alunos à experiência prática na Administração Pública para minimizar a dicotomia entre teoria e prática, e ao nos basearmos nos aspectos apontados pelos teóricos sobre a aprendizagem situada e pela experiência, identificamos o Estágio Curricular como de grande importância para a aprendizagem dos alunos.

Diante desse quadro, como também foi destacado por Freitas e Bertrand (2006), destacamos a necessidade de revisão do papel do professor no ensino a distância. No ensino a distância, a busca por tentar transferir conhecimento ao aluno deve ser substituída por uma 
postura de orientação, possibilitando que este se perceba e atue como protagonista de sua aprendizagem. Neste intento, cabe ao professor desenvolver uma comunicação bidirecional com o aluno instigando-o por meio de debates e questionamentos. Caso o professor não assuma esta postura, dificilmente a noção de que o direcionamento da aprendizagem, da leitura correta, e do melhor caminho a ser seguido, será quebrada. Por outro lado, a desestruturação e pouca concatenação do material adotado (muitas vezes considerados como de número elevado) torna confusa a construção de direcionamentos por parte do aluno, podendo levá-los a frustrações, desencadeando em um fracasso psicológico e em bloqueios para maiores aprofundamentos em busca de novas compreensões da realidade.

Como limitação da pesquisa, destaca-se que, uma vez que os depoimentos foram postados na plataforma Moodle, tornou mais difícil a análise dos discursos e uma melhor interpretação da pragmática da linguagem presente nos mesmos. Por fim, são apontadas como possibilidades, a pesquisa de outras fontes de interação entre professor, tutores e alunos, assim como de novos recursos tecnológicos que possibilitem maior suporte ao processo de ensinoaprendizagem a distância. Além disso, poderiam ser testadas e avaliadas formas de incentivo à criação de comunidades de prática, bem como a avaliação de seus resultados efetivos no sentido da aprendizagem dos alunos.

\section{REFERÊNCIAS}

CANDY, P. Understanding the individual nature of learning. In: Self direction for

lifelong learning: a comprehensive guide to theory and practice. San Francisco: Jossey-Bass, 1991, p. 249-278.

CAPES - Coordenação de Aperfeiçoamento de Pessoal de Nível Superior. Universidade Aberta do Brasil. Disponível em: $<$ http://www.uab.capes.gov.br/index.php?option=com content\&view=article\&id=6\&Itemid=18> . Acesso em: 23 de abr. de 2013.

DEWEY, J. Educação e Experiência. 3. ed. São Paulo: Ed. Nacional, 1979.

FAE, Rogério. Processo de Aprendizagem com Base no Ensino a Distância. In: Anais do XXX Encontro da ANPAD. Salvador: ANPAD, 2006.

FLEURY, A.; FLEURY, M. A competência e aprendizagem organizacional. In:

Estratégias empresariais e formação de competências: um quebra-cabeça caleidoscópio da indústria brasileira. 2. ed. São Paulo: Atlas, 2001, p. 17-33.

FREIRE, Paulo. Pedagogia da Autonomia: saberes necessários à prática educativa. São Paulo: Paz e Terra, 1996. 
FREITAS, Angilberto S.; BERTRAND, Hélêne. Ensino à Distância no Brasil: Avaliação de uma Parceria Universidade-Empresa. In: Anais do XXX Encontro da ANPAD. Salvador: ANPAD, 2006.

GHERARDI, Silvia; NICOLINI, D; ODELLA, F. Toward a social understanding of how people lean in organizations. Management Learning, v. 29, n. 3, p. 273-297, 1998;

GODOY, Arilda S. Estudo de caso qualitativo. In: GODOI, C. K., BANDEIRA-DE-MELO, R.; SILVA, A. B. (Org.) Pesquisa Qualitativa em Estudos Organizacionais: paradigmas, estratégias e métodos. São Paulo: Saraiva, 2006.

JARVIS, P. Meaningful and Meaningless Experience: toward an analysis of learning from life. Adult Education Quarterly, v. 37, n. 3, p. 164-172, Spring, 1987.

KOLB, David A. Management and the learning process. California Management Review (pre-1986); Spring 1976; 18, 000003; ABI/INFORM Global p. 21

LAVE, J.; WENGER, E. Situated learning: legitimate peripheral participation. Cambridge, UK: Cambridge University Press, 1991. p. 27-58; p. 89-101.

LEHESVIRTA, T. Learning processes in a work organization. From individual to collective and/or vice versa? Journal of workplace Learning, v. 16, n. 1/2, p.92-100, 2004.

MATURANA, Humberto R.; VARELA, Francisco J. G. A Árvore do Conhecimento: as bases biológicas da compreensão humana. São Paulo: Palas Athena, 3. ed. 2001.

MERRIAN, S.; CAFFARELLA, R. Key theories of learning. In: Coleção Harvard de Administração. Learning in adulthood: a comprehensive guide. San Francisco: Jossy-Bass. 2. ed. Cap. 11, p. 248-256, 1999.

MEZIROW, J. Making meaning: the dynamics of learning. In: Transformative dimensions of adult learning. San Francisco: Jossy-Bass, 1991, p. 1-7; p. 10-15.

MOURA, Guilherme L. Relações de conhecimento consultor organizacional-cliente à luz da Biologia do Conhecer: uma reinterpretação para desfazer mal-entendidos correntes. Dissertação (Mestrado) - Universidade Federal de Pernambuco. Programa de Pós-graduação em Administração, janeiro, 2005.

RODRIGUES, Rosângela S. Modelo de planejamento para cursos de pós-graduação à distância em cooperação universidade-empresa - Tese de Doutorado - Dep. de Eng. de Produção, UFSC, Florianópolis, 2004.

VERGARA, Sylvia C. Métodos de Pesquisa em Administração. 3 ed. São Paulo: Atlas, 2008.

Yin, Robert K. Estudo de Caso: planejamento e métodos. 2 ed. Porto Alegre: Bookman, 2001. 